\title{
ROX Index as a Predictor of Intubation Risk and 28-Day Mortality in COVID-19 Patients with Acute Respiratory Distress Syndrome
}

\author{
Putra Kurnia Nugraha ${ }^{1}$, Arie Utariani2*, \\ Philia Setiawan ${ }^{3}$, Bambang Pujo Semedi ${ }^{4}$
}

${ }^{1}$ Anesthesiologist; Department of Anesthesiology and Intensive Therapy; Faculty of Medicine Universitas Airlangga; Dr. Soetomo General Hospital Surabaya

${ }^{2}$ Consultant of Pediatric Anesthesia; Department of Anesthesiology and Intensive Therapy;

Faculty of Medicine Universitas Airlangga; Dr. Soetomo General Hospital Surabaya

${ }^{3}$ Consultant of Cardiovascular Anesthesia \& Intensive Care; Department of Anesthesiology and

Intensive Therapy; Faculty of Medicine Universitas Airlangga; Dr. Soetomo General Hospital Surabaya

${ }^{4}$ Consultant of Intensive Care; Department of Anesthesiology and Intensive Therapy;

Faculty of Medicine Universitas Airlangga; Dr. Soetomo General Hospital Surabaya

*Corresponding author details: Arie Utariani; arieutariani1955@gmail.com

\begin{abstract}
Background: The main concern when treating COVID-19 acute respiratory distress syndrome (ARDS) during high flow nasal cannula (HFNC) is delayed intubation, thus increasing the risk of prior mortality. This study aims to analyze the prognostic ability of the Respiratory Rate Oxygenation (ROX) index as a predictor for intubation and 28-days mortality in COVID-19 patients.

Methods: A retrospective analysis of COVID-19 patients admitted to Intensive Care Unit (ICU) Dr. Soetomo General Hospital in Surabaya from July to December 2020 with ARDS. The ROX indices were recorded at the 1st hour, 2nd, 4th, 6th, 12th, 18th, 24th, and 48th hours of treatment in ICU with HFNC. Identification of ROX association with HFNC failure led to intubation and 28-days mortality was through Cox proportional hazards regression. The most specific cut-off of the ROX index for predicting intubation and 28-days mortality was assessed.

Result: Among 78 patients who met the inclusion criteria, 26 (33.3\%) patients required intubation. Out of 26 patients, six patients were extubated and had survived. The 28-days mortality rate is $20(25.6 \%)$ patients. The ROX index at 12 th hours (ROX-12) $\leq 4.85$ (AUC 0.857; p $<0.001$; HR 4.7) and the ROX index at 48th hours (ROX48 ) $\leq 5.68$ (AUC 0.858; $\mathrm{p}<0.001$; HR 5.4) can accurately predict the need for intubation. ROX-12 $\leq 4.745$ is a predictor of 28-days mortality (AUC 0.85 , $\mathrm{p}<0.001$; HR 10.2).

Conclusion: ROX index predicts the risk of intubation and 28-days mortality especially ROX-12 and ROX-48. Utilization of ROX index for rapid assessment of the respiratory deterioration in COVID-19 is recommended.
\end{abstract}

Keywords: ROX Index; HFNC; Intubation; ARDS; COVID-19

\section{INTRODUCTION}

Cases of pneumonia with the cause of coronavirus infection emerged in Wuhan, Hubei Province, China in late December 2019.[1] Since then, the number of cases has increased rapidly, marked by 44 new case reports in less than a week. In less than a month, this disease quickly spread to various provinces in China, Japan, South Korea, and Thailand.[2] WHO has officially named this disease coronavirus disease 2019 (COVID-19), which is caused by the Severe Acute Respiratory Disease Coronavirus-2 (SARS-CoV-2) virus.[3] This disease is a global health problem with a high rate of human-to-human transmission and has spread widely in China and 190 other countries.[4] Due to the high rate of infection transmission, WHO has declared COVID-19 as a world pandemic.[5] In Indonesia as of January 20, 2021, there were 927,380 active cases with a death rate of 26,590 cases (WHO Indonesia, 2020). The mortality rate in Indonesia is $2.8 \%$ and is one of the highest mortality rates in Southeast Asia.[6]
Most cases of COVID-19 patients experience dyspnea and respiratory deterioration due to acute hypoxemic respiratory failure (AHRF). Silent hypoxemia is a phenomenon characterized by a dissociation between oxygen saturation (Sp02) and ventilatory dynamics in critically ill COVID-19 patients.[7, 8] Oxygen therapy is the first choice of management of COVID-19 related to AHRF.[9, 10] Non-invasive oxygen therapy such as noninvasive ventilation (NIV) or high flow nasal cannulae (HFNC) is well tolerated, and proven to be effective to treat hypoxemic respiratory failure.[11, 12] The reason for using HFNC is because it is effective, non-invasive, and more convenient.[13] Nevertheless, in critically-ill patients and severe ARDS, the HFNC/NIV most likely fail and the recommended course of action is invasive mechanical ventilation (IMV). Recent data show that the use of HFNC in COVID-19 was correlated with the lower need for intubation, shorter hospital length of stay (LOS), and lower mortality rates in comparison with standard oxygen therapy, but no different with NIV. [14-16] 
These positive results followed physiological studies showing improved oxygen supply, elimination of physiologic deadspace of the upper airway, lung mechanics, and comfort associated with HFNC. $[17,18]$ COVID-19 pneumonia is the frequent cause of ARDS during the pandemic and this has led physicians to attempt this technique.

The main concern of the increasing use of HFNC in critically-ill COVID-19 ARDS is the risk of delaying needed intubation. Delayed intubation can lead to a worse outcome and prior death. Moreover, there are no validated and approved intubation criteria for COVID-19 associated with ARDS. These may lead to considerable differences among physicians in terms of the timing of intubation that could affect the outcome.[19] ROX is an index that can predict the risk of HFNC failure in severe pneumonia[12], yet it had not been validated to COVID-19 ARDS.[20] There are many different results between studies regarding the ROX cut-off to predict HFNC failure in COVID-19 and it remains debated.[20-22]

\section{METHODS}

This is a retrospective observational study. The data were recorded from medical records of COVID-19 patients admitted to ICU Dr. Soetomo General Hospital in Surabaya, Indonesia, from July to December 2020. Adult patients with the age of $\geq 18$ years, confirmed COVID-19 by polymerase chain reaction (PCR) test, and the $\mathrm{PaO} 2 / \mathrm{FiO} 2$ ratio $<300 \mathrm{mmHg}$ were included. Patients with an immediate indication of intubation and/or rejecting treatment were excluded. We also excluded pregnant patients and incomplete medical records from this study. ROX indices were assessed at the 1st hour (ROX-1), 2nd (ROX-2), 4th (ROX-4), 6th (ROX-6), 12th (ROX-12), 18th (ROX-18), 24th (ROX-24), and 48th hours (ROX-48) during treatment in ICU. We used the ARDS criteria (Berlin's Criteria) based on the $\mathrm{PaO} 2 / \mathrm{FiO} 2$ ratio to assess the severity of the respiratory failure [23]. Identification of ROX association with HFNC failure led to intubation and 28-days mortality was through Cox proportional hazards regression. We assessed the most specific cut-off of the ROX index to predict the risk of intubation and 28-days mortality.
This study was approved and obtained ethical clearance by the Ethical Committee of Clinical Research Unit, Dr. Soetomo General Hospital, Surabaya Number 0009/KEPK/VI/2020.

Statistical analysis of this study was conducted using IBM Statistical Package for the Social Sciences (SPSS) Statistics Version 26th. Kolmogorov-Smirnov test is done for the normality test. Quantitative variables are presented as mean \pm standard deviation (SD), median (interquartile range). The categorical variables are presented as frequency (percentage). We used Student T-test or Mann-Whitney test to compare the continuous variables as appropriate. Pearson chi-square or Fisher exact test were assessed to find the differences between categorical variables. Receiver operating characteristic curves (ROCs) were performed to assess the accuracy of different variables for correctly classifying patients who would succeed or fail on HFNC. The areas under the curves (AUCs) were also calculated. ROX index's ability and cut-off to predict intubation and mortality were analyzed sensitivity, specificity, Positive Predicted Value (PPV), Negative Predicted Value (NPV), Likelihood Ratio positive (LR+), Likelihood Ratio negative (LR-) analysis. The relative risk (RR) of intubation and 28-days mortality were analyzed with the Pearson Chi-Square test. To identify if the ROX index was associated with the need for mechanical ventilation and 28-days mortality. Cox proportional hazards modeling was chosen to adjust other covariates simultaneously.

\section{RESULT}

A total of 78 eligible patients of COVID-19 with ARDS were treated with HFNC. Table 1 are presenting the baseline characteristics of participants. The median age is 47.7 years old and most of the participants are male. There are 20 obese patients and three morbidly obese patients. Diabetes and hypertension are the most comorbidities among the participants. 45 participants with moderate ARDS and 23 participants with severe ARDS. 26 patients were intubated after HFNC failure according to the clinical assessment of the attending physician. During treatment, six patients were successfully extubated after mechanical ventilation and discharged from the hospital while 20 patients did not survive.

TABLE 1: Baseline characteristics of the participants.

\begin{tabular}{|c|c|c|}
\hline Characteristics & $n=78(\%)$ & Mean ( \pm SD) / Median (IQR) \\
\hline Age (years) & & $47.75( \pm 13.39)^{\mathrm{a}}$ \\
\hline \multicolumn{3}{|l|}{ Sex } \\
\hline Male & $53(66.3)$ & \\
\hline Female & $25(33.3)$ & \\
\hline Weight (kgs) & & $72(63-85.75)^{b}$ \\
\hline BMI & & $26.42(23.51-31.12)^{\mathrm{b}}$ \\
\hline Normal & $28(36.3)$ & \\
\hline Overweight & $27(33.8)$ & \\
\hline Obesity & $20(26.3)$ & \\
\hline Morbid Obesity & $3(3.8)$ & \\
\hline \multicolumn{3}{|l|}{ Comorbidities } \\
\hline Geriatric & $10(12,5)$ & \\
\hline Diabetes & $34(42.5)$ & \\
\hline Hypertension & $6(8.8)$ & \\
\hline Cardiac disease & $7(8.8)$ & \\
\hline Chronic lung disease & $1(1.3)$ & \\
\hline Liver disease & $8(10)$ & \\
\hline Neurological disease & $3(3.8)$ & \\
\hline Chronic kidney disease & $2(2.5)$ & \\
\hline Autoimmune disorder & $1(1.3)$ & \\
\hline
\end{tabular}




\begin{tabular}{|c|c|c|}
\hline Characteristics & $n=78(\%)$ & Mean $( \pm S D) /$ Median (IQR) \\
\hline SOFA Score & & $4(3-4)^{b}$ \\
\hline PSI Score & & $66.45( \pm 28.48)^{\mathrm{a}}$ \\
\hline Pa02/FiO2 Ratio & & $125.5(91.5-179)^{\mathrm{b}}$ \\
\hline Awake Prone & $23(28.7)$ & \\
\hline Post Ventilator & $10(12.5)$ & \\
\hline \multicolumn{3}{|l|}{ ARDS Severity } \\
\hline Mild ARDS & $10(12.5)$ & \\
\hline Moderate ARDS & $45(56.3)$ & \\
\hline Severe ARDS & $23(28.7)$ & \\
\hline HFNC duration (hours) & & $109.6( \pm 69.75)^{a}$ \\
\hline HFNC failure-intubated & $26(32.5)$ & \\
\hline Survivor & $6(7.5)$ & \\
\hline Non-survivor & $20(25)$ & \\
\hline \multicolumn{3}{|l|}{ 28-days mortality } \\
\hline Survivor & $58(73.8)$ & \\
\hline Non-survivor & $20(26.3)$ & \\
\hline ICU LOS (days) & & $8.5(6-15.75)^{\mathrm{b}}$ \\
\hline
\end{tabular}

aMean $( \pm S D)$

bMedian (IQR)

Body Mass Index (BMI); Sequential Organ Failure Assessment (SOFA) score; Pneumonia Severity Index (PSI) score; Length of Stay (LOS)

The characteristics of participants with HFNC failure and success group as well as survivor and non-survivor group are shown in Table 2 and Table 3 respectively. The HFNC failure group shows a significant correlation in the age of the participants, higher initial SOFA scores, higher initial
PSI scores, lower initial PaO2/FiO2 ratio, ARDS severity, and Length of Stay (LOS) in ICU with a p-value of 0.012, $0.01,0.016,0.002,0.019$, and 0.001 respectively (Table 2). Meanwhile, the non-survivor group also shows a similar result (Table 3).

TABLE 2: Characteristics of participants based on HFNC success or failure.

\begin{tabular}{|c|c|c|c|}
\hline Characteristics & $\begin{array}{l}\text { HFNC success } \\
\quad(n=52)\end{array}$ & $\begin{array}{l}\text { HFNC Failure-Intubated } \\
\qquad(n=26)\end{array}$ & p-value \\
\hline Age (years) & $50.67( \pm 12.92)$ & $42.19( \pm 12.93)$ & $0.012^{\mathrm{a}^{*}}$ \\
\hline \multicolumn{4}{|l|}{ Sex } \\
\hline Male & $36(69.2)$ & $17(65.4)$ & $0.732^{\mathrm{c}}$ \\
\hline Female & $16(30.8)$ & $9(34.6)$ & \\
\hline Weight (kgs) & $72(62.5-87.25)$ & $72(63.75-85)$ & $0.88^{b}$ \\
\hline BMI & $26.015(23.52-31.67)$ & $27.20(23.16-29.56)$ & $0.832^{\mathrm{b}}$ \\
\hline Normal & 17 (32.7) & $10(38.5)$ & $0.363^{\mathrm{b}}$ \\
\hline Overweight & $16(30.8)$ & $11(42.3)$ & \\
\hline Obesity & $16(30.8)$ & $5(19.2)$ & \\
\hline Morbid Obesity & 3 (5.7) & 0 & \\
\hline \multicolumn{4}{|l|}{ Comorbidities } \\
\hline Geriatric & $6(11.5)$ & $4(15.4)$ & $0.632^{\mathrm{c}}$ \\
\hline Diabetes & $24(46.1)$ & $10(38.5)$ & $0.518^{c}$ \\
\hline Hypertension & $18(34.6)$ & $11(42.3)$ & $0.508^{c}$ \\
\hline Cardiac disease & $3(5.8)$ & $4(15.4)$ & $0.161^{c}$ \\
\hline Chronic lung disease & $1(1.9)$ & 0 & $0.477^{c}$ \\
\hline Liver disease & $5(9.6)$ & $3(11.5)$ & $0.792^{\mathrm{c}}$ \\
\hline Neurological disease & $1(1.9)$ & $2(7.7)$ & $0.212^{\mathrm{c}}$ \\
\hline Chronic kidney disease & 0 & $2(7.7)$ & $0.043^{\mathrm{c}^{*}}$ \\
\hline Autoimmune disorder & $1(1.9)$ & 0 & $0.477^{c}$ \\
\hline SOFA Score & $3.5(3-4)$ & $4(4-5)$ & $0.01^{b^{*}}$ \\
\hline PSI Score & $62.6( \pm 25.6)$ & $77.42( \pm 30.37)$ & $0.016^{\mathrm{a}^{*}}$ \\
\hline Initial Pa02/FiO2 Ratio & $148(108.75-186.5)$ & $100(69.75-143.5)$ & $0.002^{\mathrm{b}^{*}}$ \\
\hline Awake Prone & $14(26.9)$ & $9(34.6)$ & $0.482^{\mathrm{c}}$ \\
\hline Post Ventilator & $7(13.5)$ & $3(11.5)$ & $0.811^{\mathrm{c}}$ \\
\hline ARDS Severity & & & $0.019 \mathrm{c}^{*}$ \\
\hline Mild ARDS & $8(15.4)$ & $2(7.7)$ & \\
\hline Moderate ARDS & $34(65.4)$ & $11(42.3)$ & \\
\hline Severe ARDS & 10 (19.2) & $13(50)$ & \\
\hline
\end{tabular}




\begin{tabular}{|c|c|c|c|}
\hline Characteristics & $\begin{array}{c}\text { HFNC success } \\
\quad(n=52)\end{array}$ & $\begin{array}{l}\text { HFNC Failure-Intubated } \\
\qquad(n=26)\end{array}$ & p-value \\
\hline HFNC duration (hours) & $121.13( \pm 60.9)$ & $90.54( \pm 83.17)$ & $0.090^{\mathrm{a}^{*}}$ \\
\hline 28-days Mortality & & & $<0.001^{\mathrm{c}}$ \\
\hline Survivor & $52(100)$ & $6(23)$ & \\
\hline Non-survivor & $0(0)$ & $20(77)$ & \\
\hline LOS ICU (Days) & $7.5(5-10)$ & $16.5(11.25-23.25)$ & $<0.001^{\mathrm{b}^{*}}$ \\
\hline \multicolumn{4}{|l|}{ Initial Laboratory Finding } \\
\hline D-dimer & $1000(642-2465)$ & $1420(807.5-3075)$ & $0.170^{\mathrm{b}}$ \\
\hline Procalcitonin & $0.145(0.08-0.292)$ & $0.27(0.137-0.567)$ & $0.037 \mathrm{~b}^{*}$ \\
\hline CRP & $9.65(2.77-14.9)$ & $11.8(6.47-14.7)$ & $0.414^{b}$ \\
\hline Lactate & $1(0.7-1.44)$ & $1.22(0.8-1.47)$ & $0.435^{b}$ \\
\hline $\mathrm{pH}$ & $7.42(7.39-7.46)$ & $7.385(7.318-7.45)$ & $0.120^{\mathrm{b}}$ \\
\hline pCO2 & $36.5(29.9-44)$ & $36.35(30.45-45)$ & $1.0^{\mathrm{b}}$ \\
\hline
\end{tabular}

aMean ( \pm SD) with Independent Samples t-test, $p$-value $<0.05$

bMedian (IQR) with Mann-Whitney test, p-value $<0.05$

${ }^{c}$ Chi-square test; *p-value $<0.05$ was significantly correlated

TABLE 3: Characteristics of the survivor and non-survivor participants.

\begin{tabular}{|c|c|c|c|}
\hline Characteristics & Survivor $(n=58)$ & Non-survivor $(n=20)$ & p-value \\
\hline Age (years) & $49.4( \pm 13.8)$ & $42.8( \pm 10.7)$ & $0.051^{\mathrm{a}}$ \\
\hline \multicolumn{4}{|l|}{ Sex } \\
\hline Male & $39(67.2)$ & $14(70)$ & $0.820^{c}$ \\
\hline Female & $19(32.8)$ & $6(30)$ & \\
\hline Weight (kgs) & $74(63-90)$ & $70(62.5-77)$ & $0.262^{\mathrm{b}}$ \\
\hline BMI & $26.08(23.51-31.24)$ & $27.68(23.28-30.91)$ & $0.785^{b}$ \\
\hline Normal & $20(34.5)$ & $7(35)$ & $0.231^{c}$ \\
\hline Overweight & $17(29.3)$ & $10(50)$ & \\
\hline Obesity & $18(31)$ & $3(15)$ & \\
\hline Morbid Obesity & $3(5.2)$ & $0(0)$ & \\
\hline SOFA Score & $4(3-4)$ & $4(4-5)$ & $0.010^{\mathrm{b}^{*}}$ \\
\hline PSI Score & $61.7( \pm 26.4)$ & $79.6( \pm 30.5)$ & $0.013^{a^{*}}$ \\
\hline Pa02/FiO2 Ratio & $140(107-194)$ & $106(69.5-138)$ & $0.005^{\mathrm{b}^{*}}$ \\
\hline Awake Prone & $17(29.3)$ & $6(30)$ & $0.953^{c}$ \\
\hline Post Ventilator & $7(12.1)$ & $3(15)$ & $0.735^{c}$ \\
\hline ARDS Severity & & & $0.053^{c}$ \\
\hline Mild ARDS & $9(15.5)$ & $1(5)$ & \\
\hline Moderate ARDS & $36(62.1)$ & $9(45)$ & \\
\hline Severe ARDS & $13(22.4)$ & $10(50)$ & \\
\hline HFNC duration (hours) & $113.4( \pm 62.3)$ & $98.8( \pm 88)$ & $0.413^{\mathrm{a}}$ \\
\hline HFNC success/failure & & & $<0.001^{\mathrm{c}^{*}}$ \\
\hline HFNC failure/intubated & $6(10.3)$ & $20(100)$ & \\
\hline HFNC success & $52(89.7)$ & $0(0)$ & \\
\hline Time to intubate (hours) & $57(30.25-105.25)$ & $72.5(32.5-140.25)$ & $0.648^{b}$ \\
\hline LOS ICU (days) & $8(5-11)$ & $14(8-19.5)$ & $0.007^{b^{*}}$ \\
\hline \multicolumn{4}{|l|}{ Comorbidities } \\
\hline Geriatric & 7 (12.1) & $3(15)$ & $0.735^{c}$ \\
\hline Diabetes & $25(43.1)$ & $9(45)$ & $0.883^{c}$ \\
\hline Hypertension & $20(34.5)$ & $9(45)$ & $0.401^{\mathrm{c}}$ \\
\hline Cardiac disease & $4(6.9)$ & $3(15)$ & $0.274^{c}$ \\
\hline Chronic lung disease & $1(1.7)$ & $0(0)$ & $0.555^{c}$ \\
\hline Liver disease & $6(10.3)$ & $2(10)$ & $0.933^{c}$ \\
\hline Neurological disease & $1(1.7)$ & $2(10)$ & $0.097 \mathrm{c}$ \\
\hline Chronic kidney disease & $0(0)$ & $2(10)$ & $0.015^{c^{*}}$ \\
\hline Autoimmune disorder & $1(1.7)$ & $0(0)$ & $0.555^{c}$ \\
\hline \multicolumn{4}{|l|}{ Initial Laboratory Finding } \\
\hline D-dimer & $1130(650-2820)$ & $1280(785-2760)$ & $0.394^{b}$ \\
\hline Procalcitonin & $0.16(0.09-0.34)$ & $0.26(0.11-0.595)$ & $0.143^{\mathrm{b}}$ \\
\hline CRP & $10.1(3.1-14.8)$ & $8.3(4.25-14.9)$ & $0.943^{b}$ \\
\hline Lactate & $1.0(0.7-1.3)$ & $1.35(0.85-1.5)$ & $0.168^{b}$ \\
\hline $\mathrm{pH}$ & $7.42(7.38-7.46)$ & $7.41(7.315-7.445)$ & $0.194^{\mathrm{b}}$ \\
\hline pCO2 & $36.7(29.6-44)$ & $36.2(31.25-44)$ & $0.943^{\mathrm{b}}$ \\
\hline
\end{tabular}


aMean ( \pm SD) with Independent Samples t-test, p-value $<0.05$ bMedian (IQR) with Mann-Whitney test, p-value $<0.05$

chi-square test, *p-value $<0.05$ was significantly correlated.

ROX index's ability as a predictor of HFNC failure that led to intubation and 28-days mortality are listed in Table 4 ROX index in each hour has significant results in predicting the intubation and 18-days mortality, both with a p-value of 0.001 ).
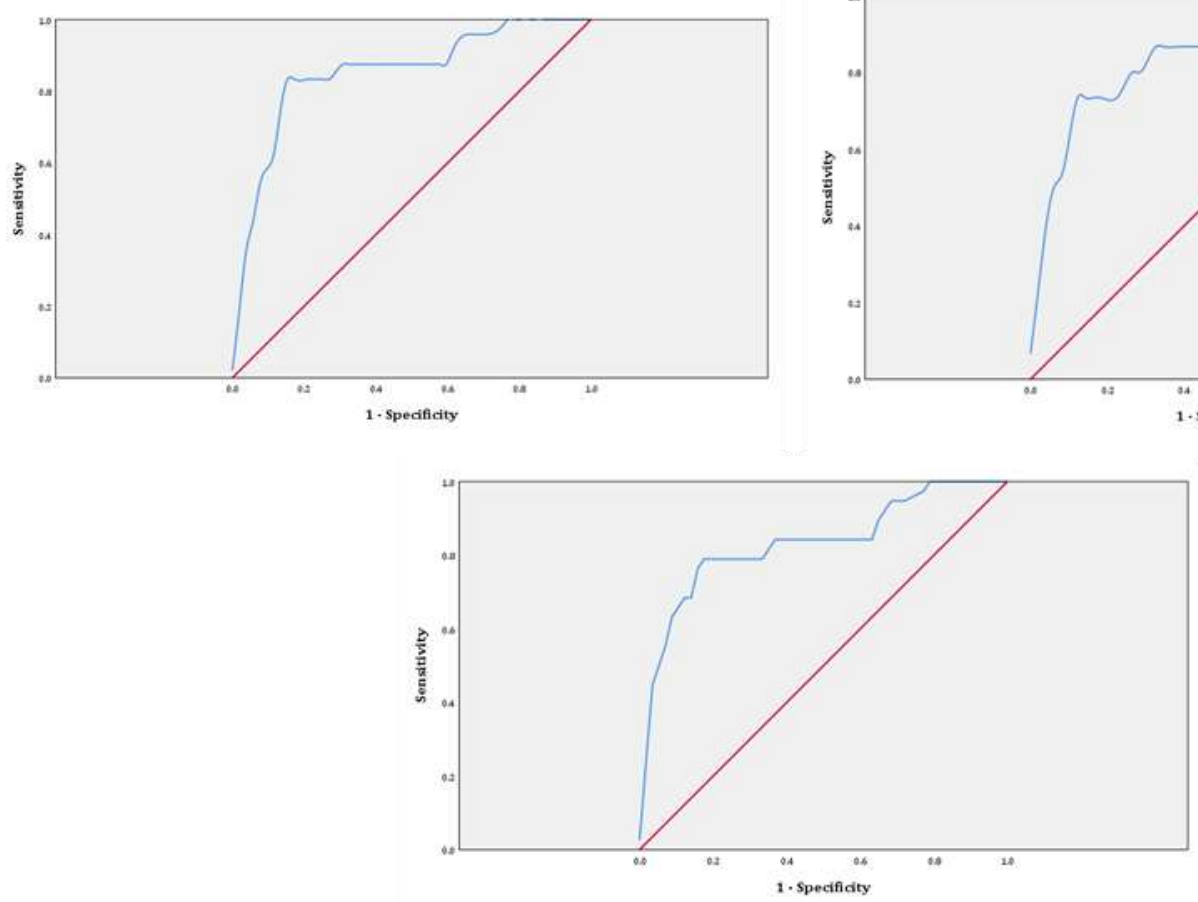

FIGURE 1: The ROC test analysis of ROX index at hour 12th (A) and hour 48th (B) on the incidence of intubation, and the ROX index at hour 12th (C) of 28-days mortality.

The most specific cut-off of the ROX index to predict intubation and 28-days mortality were both ROX-12 and ROX-48. Cox proportional hazards regression adjusted with other ROX indices. The results are both ROX-12 and

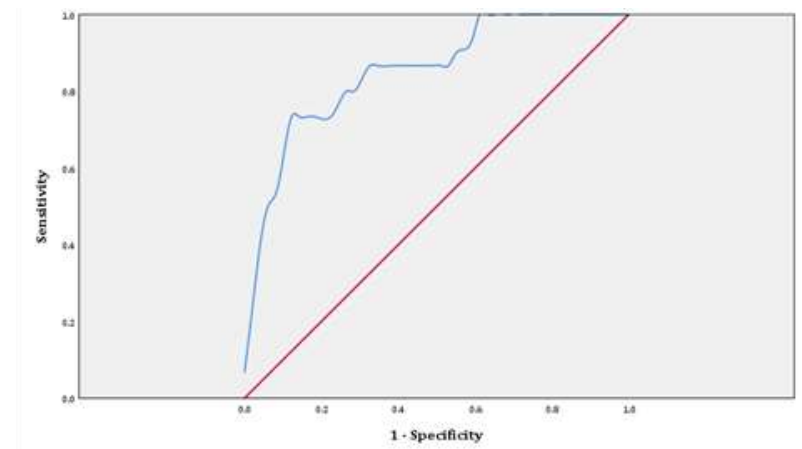

ROX-12 and ROX-48 have the highest AUC both in predicting intubation ( 0.857 and 0.858 respectively) and 28-days mortality ( 0.858 and 0.853 respectively) (Figure 1). Thereafter, Table 4 also showed ROX-12 and ROX-48 have the highest relative risk (RR) predicting the risk of intubation and 28-days mortality 8.448 and 7.0; 7.556 and 6.667 respectively.

Spedfiaity
ROX-48 can be used as a predictor of intubation in COVID19 ARDS. Also, ROX-12 with different cut-off points ( $\leq$ 4.745 ) can be used as a predictor of 28-days mortality (Table 5).

TABLE 4 : Sensitivity, Specificity, PPV, NPV, LR+, and LR- of ROX Index in finding the risk of Intubation and 28-days Mortality.

\begin{tabular}{|c|c|c|c|c|c|c|c|c|c|c|}
\hline ROX index & Cut-off & AUC & Se (\%) & Sp (\%) & $\begin{array}{l}\text { PPV } \\
\text { (\%) }\end{array}$ & $\begin{array}{l}\text { NPV } \\
\text { (\%) }\end{array}$ & LR+ & LR- & $\mathbf{R R}$ & p-value \\
\hline \multicolumn{11}{|l|}{ Hour-1 } \\
\hline Intubation & 4.54 & 0.760 & 73.08 & 74.07 & 57.58 & 85.11 & 2.82 & 0.36 & 3.866 & $<0.001^{*}$ \\
\hline Mortality & 4.49 & 0.795 & 71.43 & 72.88 & 48.39 & 87.76 & 2.63 & 0.39 & 3.952 & $0.001^{*}$ \\
\hline \multicolumn{11}{|l|}{ Hour-2 } \\
\hline Intubation & 4.74 & 0.769 & 73.08 & 72.22 & 55.88 & 84.78 & 2.63 & 0.37 & 3.672 & $<0.001^{*}$ \\
\hline Mortality & 4.49 & 0.800 & 76.19 & 77.97 & 55.17 & 90.20 & 3.46 & 0.31 & 5.628 & $<0.001^{*}$ \\
\hline \multicolumn{11}{|l|}{ Hour-4 } \\
\hline Intubation & 4.65 & 0,746 & 69.23 & 70.37 & 52,94 & 82.61 & 2.34 & 0.44 & 3.044 & $0.001^{*}$ \\
\hline Mortality & 4.56 & 0.762 & 71.43 & 71.19 & 46.87 & 87.50 & 2.48 & 0.40 & 3.750 & $0.001^{*}$ \\
\hline \multicolumn{11}{|l|}{ Hour-6 } \\
\hline Intubation & 4.72 & 0.772 & 76.92 & 75.93 & 60.61 & 87.23 & 3.20 & 0.30 & 4.747 & $<0.001^{*}$ \\
\hline Mortality & 4.48 & 0.763 & 71.43 & 72.88 & 48.39 & 87.76 & 2.63 & 0.39 & 3.952 & $0.001^{*}$ \\
\hline \multicolumn{11}{|l|}{ Hour-12 } \\
\hline Intubation & 4.85 & 0.857 & 83.33 & 83.33 & 68.97 & 91.84 & 5.0 & 0.20 & 8.448 & $<0.001^{*}$ \\
\hline Mortality & 4.745 & 0.858 & 80.0 & 81.03 & 59.26 & 92.16 & 4.22 & 0.25 & 7.556 & $<0.001^{*}$ \\
\hline \multicolumn{11}{|l|}{ Hour-18 } \\
\hline Intubation & 5.16 & 0.830 & 75.0 & 74.07 & 56.25 & 86.96 & 2.89 & 0.34 & 4.313 & $<0.001^{*}$ \\
\hline Mortality & 5.04 & 0.819 & 75.0 & 74.14 & 50.0 & 89.58 & 2.90 & 0.34 & 4.80 & $<0.001^{*}$ \\
\hline \multicolumn{11}{|l|}{ Hour-24 } \\
\hline Intubation & 4.925 & 0.777 & 56.52 & 81.48 & 56.52 & 81.48 & 3.05 & 0.53 & 3.052 & $0.001^{*}$ \\
\hline Mortality & 5.255 & 0.796 & 73.68 & 74.14 & 48.28 & 89.58 & 2.85 & 0.35 & 4.634 & $0.001^{*}$ \\
\hline
\end{tabular}




\begin{tabular}{lcccccccccc}
\hline ROX index & Cut-off & AUC & Se (\%) & Sp (\%) & $\begin{array}{c}\text { PPV } \\
(\%)\end{array}$ & $\begin{array}{c}\text { NPV } \\
(\%)\end{array}$ & LR+ & LR- & RR & p-value \\
\hline $\begin{array}{l}\text { Hour-48 } \\
\text { Intubation }\end{array}$ & 5.68 & 0.858 & 80.0 & 76.47 & 50.0 & 92.86 & 3.40 & 0.26 & 7.0 & $<0.001^{*}$ \\
Mortality & 5.525 & 0.853 & 76.92 & 77.36 & 45.45 & 93.18 & 3.40 & 0.3 & 6.667 & $0.001^{*}$ \\
\hline
\end{tabular}

*p-value $<0.05$ are significantly correlated; ROC curves; Pearson Chi-Square was used.

TABLE 5: Cox Proportional Hazards Regression of ROX Index Predicting Intubation and 28-Days Mortality

\begin{tabular}{|c|c|c|c|c|c|c|c|c|}
\hline \multirow{2}{*}{$\begin{array}{c}\text { ROX } \\
\text { index }\end{array}$} & \multicolumn{4}{|c|}{ Intubation } & \multicolumn{4}{|c|}{ 28-days Mortality } \\
\hline & HR & $\begin{array}{c}\text { Corr. } \\
\text { Coefficient }\end{array}$ & $95 \% \mathrm{CI}$ & p-value & HR & $\begin{array}{c}\text { Corr. } \\
\text { Coefficient }\end{array}$ & $95 \%$ CI & $\begin{array}{c}\text { p- } \\
\text { value }\end{array}$ \\
\hline Hour-1 & - & - & - & 0.545 & - & - & - & 0.142 \\
\hline Hour-2 & - & - & - & 0.237 & - & - & - & 0.123 \\
\hline Hour-4 & - & - & - & 0.930 & - & - & - & 0.184 \\
\hline Hour-6 & - & - & - & 0.335 & - & - & - & 0.253 \\
\hline Hour-12 & 4.707 & 1.549 & $1.389-15.945$ & $0.013^{*}$ & 10.286 & 2.331 & $2.774-38.132$ & $\begin{array}{c}<0.00 \\
1^{*}\end{array}$ \\
\hline Hour-18 & - & - & - & 0.728 & - & - & - & 0.996 \\
\hline Hour-24 & - & - & - & 0.264 & - & - & - & 0.964 \\
\hline Hour-48 & 5.469 & 1.699 & $1.424-21.011$ & $0.013^{*}$ & - & - & - & 0.081 \\
\hline
\end{tabular}

*p-value $<0.05$ are significantly correlated; Cox proportional hazards regression forward LR test.

\section{DISCUSSION}

The respiratory complication of SARS-CoV2 viral infection can lead to ARDS. ARDS related to COVID-19 shows an unusual phenotype and different characteristics from classic ARDS. There is a dissociation between the hypoxemia severity and the relatively good respiratory mechanics which are called silent hypoxemia.[7, 24] Silent hypoxemia potentially causes prolonged hypoxemia, and thus rapid and precise clinical assessment and treatment become necessary.

Predicting the outcome of critically-ill COVID-19 patients treated with HFNC is a major challenge for every physician. HFNC is a non-invasive oxygen treatment that is effective and excels in patients' comfort in comparison to NIV Compared to standard oxygen therapy and NIV, HFNC showed better results for lower intubation rates in patients with $\mathrm{PaO} 2 / \mathrm{FiO} 2 \leq 200 \mathrm{mmHg}$.[25] HFNC can prevent patient self-induced lung injury (P-SILI) by improving oxygenation and reducing the work of breathing $[11,17]$ The main concern regarding the use of non-invasive oxygen therapy of COVID-19 patients is delayed intubation.[26, 27] Consistent data shows that delayed or late intubation may worsen the outcome of patients with respiratory failure[28-30] and many suggest that early intubation seems to be the best course of action. Interestingly in COVID-19 respiratory failure, there are controversies about the timing of intubation. The right timing of intubation is a matter of great importance, but it is difficult to determine and there are not yet validated criteria for COVID-19 intubation. A recent study shows that there are no significant differences in mortality rates between the 'early' versus 'late' intubation.[16, 31] These findings suggest that the 'wait-and-see' may be the best approach for deciding the timing to intubate.

In this study, we established that ROX-12 $\leq 4.85$ and ROX$48 \leq 5.68$ are a predictor of HFNC failure, while ROX-12 $\leq$ 4.745 predicts 28 -days mortality. Additionally, we provide high sensitivity and specificity of specific cut-off points of the ROX index allowing identification of patients who need to be intubated and predicting the 28-days mortality within the first 12 hours of treatment with HFNC. These results may have the potential to improve practices in the monitoring and treatment of COVID-19 patients treated with HFNC. COVID-19 patients with the ROX index below the cut-off value (ROX-12 $\leq 4.745)$ have a greater risk of 28-days mortality by 7.5 times compared to the patients with the ROX index above the cut-off value. Thus, it is recommended to re-evaluate the need to intubate to prevent prolonged hypoxemia and worse outcome.

Numerous studies have different cut-off values of the ROX index.[22, 32, 33] This may be due to differences in samples, data collection methods, data processing methods, and patient treatments. The experience and the decision-making of the physician in charge may also vary. Therefore, it is difficult to determine a uniform cut-off value due to the different variability. ROX index in COVID19 are widely used and yet it somewhat differs from the proposed cut-off point by Roca.[12] Studies in several countries reported that cut-off points $<5$ in the first 12 hours of treatment were strongly associated with HFNC failure that can lead to intubation and mechanical ventilation.[21, 22] Study in Egypt measuring the ROX index to predict the intubation in COVID-19 patients on day 1 to day 3 reported that ROX index at day 3 to hour-72 has cut-off point $\leq 11.71$, sensitivity $90 \%$, specificity $100 \%$, PPV 100\%, NPV 87.5\% and AUC 0.975.[33]

Data from our studies regarding the time of intubation shows that most intubations occur between the first $12^{\text {th }}$ and the $48^{\text {th }}$ hour. We, therefore recommend monitoring the ROX index over time with a focus from the $12^{\text {th }}$ hour ahead: the risk of failure is high if less than 4.85 , and intubating the patient should be considered. Interestingly, there are two cut-off points in ROX-12 in this study, A zone exists between 4.745 and 4.85 . It may suggest if the patient ROX index is between 4.745 and 4.85 , then the patient is at risk of HFNC failure but not yet at risk for 28-days mortality. Further study needs to be conducted to confirm this opinion. To our knowledge, this is the first study to assess the ROX prognostic ability for 28-days mortality in COVID-19.

Our study has several limitations. First, COVID-19 confirmed participants in this study are based on the result of a positive PCR. PCR is considered to be the gold standard of the confirmed COVID-19 diagnostic,[34, 35] but we cannot dismiss the existence of false-positive and/or falsenegative results. Second, because there is yet no validated or standardization of intubation criteria specific for COVID-19 with ARDS, and the outcome of mechanical ventilation might be somewhat subjective. 
Third, the sample collected in this study may not represent the population affected by the pandemic, especially the collected data from the first wave of the pandemic in Surabaya, Indonesia. Fourth, the data extractors were not blinded and may be biased in interpreting the data. Finally, this is a retrospective study with the methodological drawbacks it may entail.

\section{CONCLUSION}

ROX index is a useful means to predict HFNC failures leading to intubation (ROX-12 and ROX-48) and 28-days mortality (ROX-12). The ROX index is non-invasive, simple, particularly useful to identify the risk for respiratory deterioration and to assist therapeutic decisions. Therefore, utilization of the ROX index is recommended for the rapid assessment in critically-ill COVID-19 patients.

\section{REFERENCES}

[1] Rothan HA, Byrareddy SN: The epidemiology and pathogenesis of coronavirus disease (COVID-19) outbreak. Journal of autoimmunity 2020, 109:102433.

[2] Huang C, Wang Y, Li X, Ren L, Zhao J, Hu Y, Zhang L, Fan G, Xu J, Gu X: Clinical features of patients infected with 2019 novel coronavirus in Wuhan, China. The lancet 2020, 395(10223):497-506.

[3] World Health 0: Naming the coronavirus disease (COVID-19) and the virus that causes it. Brazilian Journal of Implantology and Health Sciences 2020, 2(3).

[4] Lu H, Stratton CW, Tang YW: Outbreak of pneumonia of unknown etiology in Wuhan, China: The mystery and the miracle. Journal of medical virology 2020 , 92(4):401.

[5] World Health 0: WHO Director-General's remarks at the media briefing on 2019-nCoV on 11 February 2020. In.; 2020.

[6] Livingston E, Bucher K, Rekito A: Coronavirus disease 2019 and influenza 2019-2020. Jama 2020, 323(12):1122-1122.

[7] Gattinoni L, Chiumello D, Rossi S: COVID-19 pneumonia: ARDS or not? In., vol. 24: BioMed Central; 2020: 1-3.

[8] Gibson PG, Qin L, Puah SH: COVID-19 acute respiratory distress syndrome (ARDS): clinical features and differences from typical pre-COVID-19 ARDS. Medical Journal of Australia 2020, 213(2):54-56.

[9] Hu M, Zhou Q, Zheng R, Li X, Ling J, Chen Y, Jia J, Xie C: Application of high-flow nasal cannula in hypoxemic patients with COVID-19: a retrospective cohort study. BMC Pulmonary Medicine 2020, 20(1):1-7.

[10] Penyusun T: Protokol Tatalaksana COVID-19. Jakarta: PDPI, PERKI, PAPDI, PERDATIN, IDAI 2020:50.

[11] Nishimura M: High-flow nasal cannula oxygen therapy in adults. Journal of intensive care 2015, 3(1):1-8.

[12] Roca O, Caralt B, Messika J, Samper M, Sztrymf B, Hernández G, García-de-Acilu M, Frat J-P, Masclans JR, Ricard J-D: An index combining respiratory rate and oxygenation to predict outcome of nasal highflow therapy. American journal of respiratory and critical care medicine 2019, 199(11):1368-1376.
[13] Spicuzza L, Schisano M: High-flow nasal cannula oxygen therapy as an emerging option for respiratory failure: the present and the future. Therapeutic advances in chronic disease 2020, 11:2040622320920106.

[14] Duan J, Chen B, Liu X, Shu W, Zhao W, Li J, Li Y, Hong Y, Pan L, Wang K: Use of high-flow nasal cannula and noninvasive ventilation in patients with COVID-19: A multicenter observational study. The American journal of emergency medicine 2021, 46:276-281.

[15] Shoukri AM: High flow nasal cannula oxygen and non-invasive mechanical ventilation in management of COVID-19 patients with acute respiratory failure: a retrospective observational study. The Egyptian Journal of Bronchology 2021, 15(1):1-7.

[16] Mellado-Artigas R, Ferreyro BL, Angriman F, Hernández-Sanz M, Arruti E, Torres A, Villar J, Brochard L, Ferrando C: High-flow nasal oxygen in patients with COVID-19-associated acute respiratory failure. Critical Care 2021, 25(1):1-10.

[17] Laurent P, Amanda C, Dean H: Fraser John F. Frat Jean-Pierre, Guitton Christophe, Jaber Samir, Maggiore Salvatore M, Nava Stefano, Rello Jordi, Ricard Jean-Damien, Stephan François, Trisolini Rocco, Azoulay Elie Use of high-flow nasal cannula oxygenation in ICU adults: a narrative review Intensive Care Medicine 2016, 42(9):1336-1349.

[18] Shah TH, Mantoo S, Jan RA: High Flow Nasal Cannula Oxygenation. JMS SKIMS 2020, 23(3):41-44.

[19] Darreau C, Martino F, Saint-Martin M, Jacquier S, Hamel JF, Nay MA, Terzi N, Ledoux G, Roche-Campo F, Camous L: Use, timing and factors associated with tracheal intubation in septic shock: a prospective multicentric observational study. Annals of intensive care 2020, 10:1-10.

[20] Zucman N, Mullaert J, Roux D, Roca O, Ricard J-D: Prediction of outcome of nasal high flow use during COVID-19-related acute hypoxemic respiratory failure. Intensive care medicine 2020, 46(10):1924-1926.

[21] Chandel A, Patolia S, Brown AW, Collins AC, Sahjwani D, Khangoora V, Cameron PC, Desai M, Kasarabada A, Kilcullen JK: High-flow nasal cannula therapy in COVID-19: using the ROX index to predict success. Respiratory care 2021, 66(6):909-919.

[22] Patel M, Chowdhury J, Mills N, Marron R, Gangemi A, Dorey-Stein Z, Yousef I, Tragesser L, Giurintano J, Gupta R: ROX Index Predicts Intubation in Patients with COVID-19 Pneumonia and Moderate to Severe Hypoxemic Respiratory Failure Receiving High Flow Nasal Therapy. medRxiv 2020.

[23] Force ADT, Ranieri VM, Rubenfeld GD, Thompson BT, Ferguson N, Caldwell E, Fan E, Camporota L, Slutsky AS: Acute respiratory distress syndrome. Jama 2012, 307(23):2526-2533.

[24] Levitan RM: Pulse Oximetry as a Biomarker for Early Identification and Hospitalization of Covid Pneumonia. Academic Emergency Medicine 2020.

[25] Panadero C, Abad-Fernández A, Rio-Ramirez MT, Gutierrez CMA, Calderon-Alcala M, Lopez-Riolobos C, Matesanz-Lopez C, Garcia-Prieto F, Diaz-Garcia JM, Raboso-Moreno B: High-flow nasal cannula for Acute Respiratory Distress Syndrome (ARDS) due to COVID-19. Multidisciplinary respiratory medicine 2020, 15(1). 
[26] Hernandez-Romieu AC, Adelman MW, Hockstein MA, Robichaux CJ, Edwards JA, Fazio JC, Blum JM, Jabaley CS, Caridi-Scheible M, Martin GS: Emory COVID-19 Quality and Clinical Research Collaborative. Timing of intubation and mortality among critically ill coronavirus disease 2019 patients: a single-center cohort study. Crit Care Med 2020, 48(11): e10451053.

[27] Lee YH, Choi K-J, Choi SH, Lee SY, Kim KC, Kim EJ, Lee $\mathrm{J}$ : Clinical significance of timing of intubation in critically ill patients with Covid-19: A multi-center retrospective study. Journal of clinical medicine 2020, 9(9):2847.

[28] Bauer PR, Gajic O, Nanchal R, Kashyap R, MartinLoeches I, Sakr Y, Jakob SM, François B, Wittebole X, Wunderink RG: Association between timing of intubation and outcome in critically ill patients: A secondary analysis of the ICON audit. Journal of critical care 2017, 42:1-5.

[29] Kang BJ, Koh Y, Lim C-M, Huh JW, Baek S, Han M, Seo H-S, Suh HJ, Seo GJ, Kim EY: Failure of high-flow nasal cannula therapy may delay intubation and increase mortality. Intensive care medicine 2015, 41(4):623632.

[30] Kangelaris KN, Ware LB, Wang CY, Janz DR, Hanjing Z, Matthay MA, Calfee CS: Timing of Intubation and Clinical outcomes in Adults with ARDS. Critical care medicine 2016, 44(1):120.
[31] Papoutsi E, Giannakoulis VG, Xourgia E, Routsi C, Kotanidou A, Siempos II: Effect of timing of intubation on clinical outcomes of critically ill patients with COVID-19: a systematic review and meta-analysis of non-randomized cohort studies. Critical Care 2021, 25(1):1-9.

[32] Lemiale V, Dumas G, Demoule A, Pène F, Kouatchet A, Bisbal M, Nseir S, Argaud L, Kontar L, Klouche K: Performance of the ROX index to predict intubation in immunocompromised patients receiving highflow nasal cannula for acute respiratory failure. Annals of intensive care 2021, 11(1):1-9.

[33] Suliman LA, Abdelgawad TT, Farrag NS, Abdelwahab HW: Validity of ROX index in prediction of risk of intubation in patients with COVID-19 pneumonia. Advances in Respiratory Medicine 2021, 89(1):1-7.

[34] World Health O: Laboratory testing for coronavirus disease ( COVID-19) in suspected human cases: interim guidance, 19 March 2020. In.: World Health Organization; 2020.

[35] Dramé M, Teguo MT, Proye E, Hequet F, Hentzien M, Kanagaratnam L, Godaert L: Should RT-PCR be considered a gold standard in the diagnosis of Covid19 ? Journal of medical virology 2020. 